\section{BRAZIULIAN JOURNAL \\ OF MEDICAL AND BIOLOGICAL RESF.ARCH}

www.bjournal.com.br
ISSN 0100-879X

Volume 42 (11) 993-1118 November 2009

BIOMEDICAL SCIENCES

AND

CLINICAL INVESTIGATION

Braz J Med Biol Res, November 2009, Volume 42(11)1090-1096

Animal model for age- and sex-related genotoxicity of diethylstilbestrol

A. Fučić, R. Stojkovic, J. Katić, D. Markovic, Z. Ferencic, M. Koršić, A.M. Jazbec and M. Gamulin

The Brazilian Journal of Medical and Biological Research is partially financed by
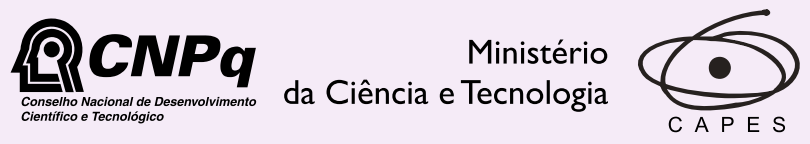

Ministério da Educação

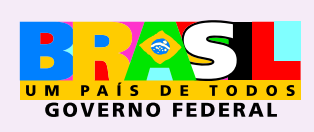

DFAPESP

Institutional Sponsors 


\title{
Animal model for age- and sex-related genotoxicity of diethylstilbestrol
}

\author{
A. Fučić ${ }^{1}$, R. Stojkovic ${ }^{2}$, J. Katić ${ }^{1}$, D. Markovic ${ }^{3}$, Z. Ferencic ${ }^{4}$, M. Koršić ${ }^{5}$, \\ A.M. Jazbec ${ }^{6}$ and M. Gamulin ${ }^{5}$ \\ ${ }^{1}$ Institute for Medical Research and Occupational Health, Zagreb, Croatia \\ 2Division of Molecular Medicine, Ruđer Bošković Institute, Zagreb, Croatia \\ ${ }^{3}$ GlaxoSmithKline Research Centre Zagreb Ltd., Zagreb, Croatia \\ ${ }^{4}$ Children's Hospital "Srebrnjak" and 5 University Hospital Zagreb, Zagreb, Croatia \\ ${ }^{6}$ Faculty of Forestry, University of Zagreb, Zagreb, Croatia
}

\begin{abstract}
Environmental xenoestrogens pose a significant health risk for all living organisms. There is growing evidence concerning the different susceptibility to xenoestrogens of developing and adult organisms, but little is known about their genotoxicity in pre-pubertal mammals. In the present study, we developed an animal model to test the sex- and age-specific genotoxicity of the synthetic estrogen diethylstilbestrol (DES) on the reticulocytes of 3-week-old pre-pubertal and 12-week-old adult BALB/ CJ mice using the in vivo micronucleus (MN) assay. DES was administered intraperitoneally at doses of $0.05,0.5$, and $5 \mu \mathrm{g} /$ $\mathrm{kg}$ for 3 days and animals were sampled 48,72 and $96 \mathrm{~h}$, and 2 weeks after exposure. Five animals were analyzed for each dose, sex, and age group. After the DES dose of $0.05 \mu \mathrm{g} / \mathrm{kg}$, pre-pubertal mice showed a significant increase in MN frequency $(\mathrm{P}<0.001)$, while adults continued to show reference values (5.3 vs $1.0 \mathrm{MN} / 1000$ reticulocytes). At doses of 0.5 and $5 \mu \mathrm{g} /$ $\mathrm{kg}, \mathrm{MN}$ frequency significantly increased in both age groups. In pre-pubertal male animals, MN frequency remained above reference values for 2 weeks after exposure. Our animal model for pre-pubertal genotoxicity assessment using the in vivo MN assay proved to be sensitive enough to distinguish age and sex differences in genome damage caused by DES. This synthetic estrogen was found to be more genotoxic in pre-pubertal mice, males in particular. Our results are relevant for future investigations and the preparation of legislation for drugs and environmentally emitted agents, which should incorporate specific age and gender susceptibility.
\end{abstract}

Key words: Diethylstilbestrol; Estrogen; Puberty; In vivo micronucleus assay; Sex; Genotoxicity

\section{Introduction}

Estrogen is a paracrine and endocrine hormone, and probably also a neurotransmitter (1) with carcinogenic properties in animals and humans (2). Human exposure to xenoestrogens is alarming. Compounds, which express estrogen-like biological effects, are present in the environment in a variety of forms, such as metalloestrogens, pesticides, polychlorinated biphenyls, pharmacological estrogens, phytoestrogens, and heavy metals $(3,4)$. Recent studies have shown that a number of radioactive, toxic, and/or genotoxic agents such as arsenic, cadmium and uranium also have estrogen-like activity. In transplacental exposure, these agents can cause cancer through mechanisms such as methylation $(4,5)$. In the environment, they create complex environmental xenobiotic mixtures, and it is crucial to understand the effects of their interaction on organisms, especially during development.

As regulatory molecules, estrogens have been associated for decades with development, homeostasis, or pathology of the reproductive system. Growing evidence about the distribution of estrogen receptors in different mammalian tissues (6) suggests that estrogens could be central in orchestrating a number of pathways in developing and adult organisms (7).

New biomedical methods and data have shown that hormones such as estrogens may act as carcinogens at non-physiological doses $(2,8)$. In addition, by decreasing glutathione-S-transferases, estrogens may increase oxidative DNA damage in estrogen-responsive tissues if the organism is simultaneously exposed to other genotoxicants, and launch carcinogenesis (9). 
About 65 agents, mostly industrial products, are known today to express estrogen-like activity (10), although estimates of the number of such compounds vary (11). One such agent is the synthetic estrogen diethylstilbestrol (DES). DES has been used to reduce the risk of miscarriage, but was banned when it was demonstrated that this drug induced neoplasms and reproductive organ malformations, decreased fertility, and led to immune system disorders in transplacentally exposed mammals of both sexes, including humans $(10,12)$.

The reactive genotoxic intermediate of DES is DES quinone (DES Q), which binds to DNA and forms chemically unstable adducts. DNA adducts caused by DES are 4-6 times more frequent in females than in males (13). DES also causes mitochondrial DNA damage specifically attacking cytochrome c oxidase (14).

In addition to chromosome rearrangements, the literature has reported the aneugenic potency of DES $(8,15)$. Similar to colchicine, DES inhibits the intra-chain crosslinking of tubulin (16). Neonatal exposure to DES may cause disturbances of gene ontogeny by demethylation, with a transgenerational effect (12).

In mammals, DES also acts as an estrogen-like compound, and affects the kidney, prostate, vagina, and cervix, causing microsatellite instability and enhancing tyrosine phosphorylation, which may affect cellular integrity and cell cycle control (17).

Since the living environment is polluted with xenoestrogens, by-products of industrial or chemical processing that have estrogen-like effects, with unknown genome damage during development, we introduced and tested a pre-pubertal animal model for genotoxicity testing using DES as a xenoestrogen with a well-known pharmacodynamic and genotoxic mechanism. Pre-pubertal and adult animals were compared using the in vivo micronucleus (MN) assay (18), which can detect clastogen and aneugen damage (Figure
1). Additionally, the model is used to determine if genome damage caused by DES differs between the sexes.

\section{Material and Methods}

The study included 3-week-old young and 12-week-old adult BALB/CJ mice obtained from a breeding colony of the Ruđer Bošković Institute (Zagreb, Croatia). During the experiment, animals were housed 4 to a cage. The bottom of the cage was covered with sawdust (Allspan ${ }^{\circledR}$, Germany). Standard food for laboratory mice (4 RF 21 GLP Mucedola srl, Italy) was used. All animals had free access to food and water. Animals were kept under standard conditions with a 12-h light/dark cycle, temperature of $22^{\circ} \mathrm{C}$, and $55 \%$ humidity. All experiments were performed according to the ILAR Guide for the Care and Use of Laboratory Animals, Council Directive (\#86/609/EEC) and Croatian Animal Protection Act (\#NN 135/06).

After the baseline MN frequency was established, each group of animals received $0.05,0.5$ or $5 \mu \mathrm{g} / \mathrm{kg}$ of DES (Sigma, USA) intraperitoneally (ip) for 3 consecutive days. Olive oil was used as a solvent. Treated animals were divided into groups of 5 each by age, sex, and treatment dose. In addition, one group of adult animals and one group of young animals of both sexes ( 5 animals each) served as positive control and received a single injection of $75 \mathrm{mg} /$ $\mathrm{kg}$ cyclophosphamide (Sigma). One group of adult animals and one of young animals of both sexes (5 animals each) served as negative control and received olive oil injections for 3 consecutive days. The animals were sampled 48, 72 and $96 \mathrm{~h}$, and 2 weeks after dosing.

Peripheral blood was collected from the tail vein $(5 \mu \mathrm{L}$ per sample) from all animals. Blood smears were prepared on acridine orange-coated slides, covered with a coverslip and analyzed according to Hayashi et al. (18). MN frequency was analyzed in 1000 reticulocytes per sample. Although
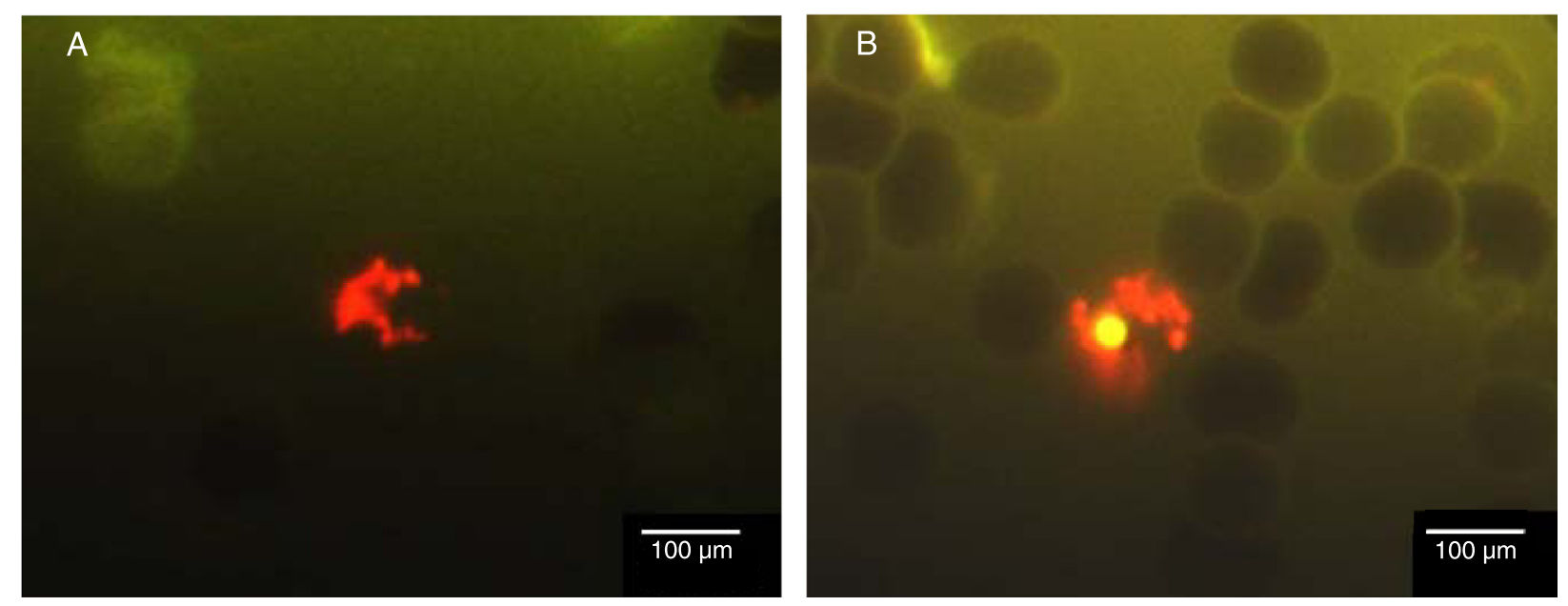

Figure 1. Reticulocyte stained with acridine orange (A) and reticulocyte-containing micronucleus (B). 


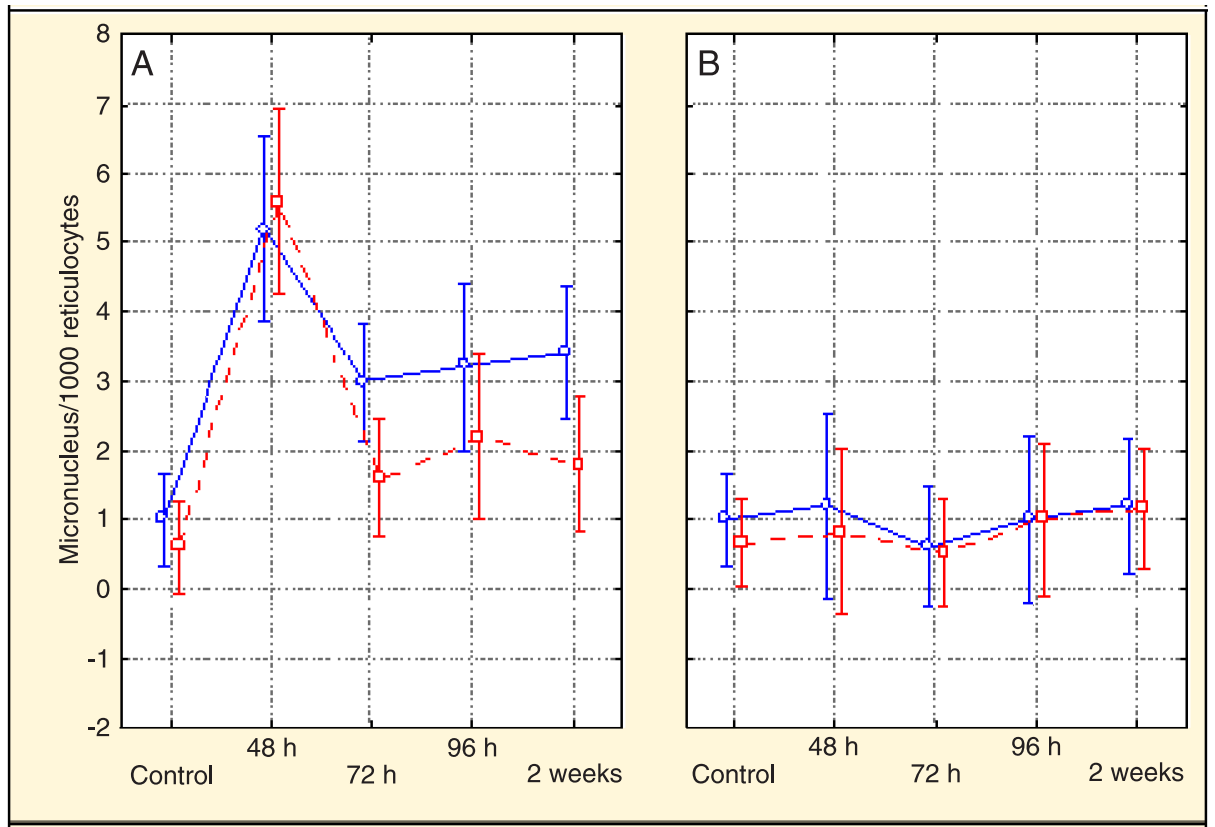

Figure 2. Micronucleus frequency in $A, 3$ - and B, 12-week-old male (blue full line) and female (red dashed line) mice exposed to $0.05 \mu \mathrm{g} / \mathrm{kg}$ diethylstilbestrol. For each dose, age and sex, 5 animals were analyzed. Micronucleus frequency is reported as per 1000 reticulocytes. Vertical bars indicate $95 \%$ confidence intervals. ANOVA for repeated measurements was used to compare responses at each sampling time.

usually there is only one micronucleus per reticulocyte, very rarely two micronuclei can be detected.

Analysis of variance (ANOVA) for repeated measurements was used to compare responses at each sampling time. Doses and groups were analyzed as fixed effects. The level of statistical significance was set at $5 \%(P<$ $0.05)$. Calculations were performed using the Statistica 6.0 software.

\section{Results}

Positive control animals exposed to cyclophosphamide showed a significant increase in $\mathrm{MN}$ frequency (61.4 \pm 5.4 MN/1000 reticulocytes) $48 \mathrm{~h}$ after treatment. The frequencies at other sampling times were similar to the baseline frequency (0.77-1.33 MN/1000 reticulocytes). Negative control animals exposed to olive oil showed no differences from baseline values (0.25-1.25 MN/1000 reticulocytes).

Three-week-old male and female mice showed a significant increase in MN frequency (5.2/1000 and 5.6/1000 reticulocytes, respectively) $48 \mathrm{~h}$ after receiving $0.05 \mu \mathrm{g} / \mathrm{kg}$ DES. At $72 \mathrm{~h}, \mathrm{MN}$ frequency had returned to baseline values in females, while in males it remained increased for as long as 2 weeks after exposure. In 12-week-old animals, MN frequency remained at baseline values (Figure 2).

At the dose of $0.5 \mu \mathrm{g} / \mathrm{kg}$, MN frequency significantly increased regardless of age or sex (Figure 3 ). The highest frequency was detected $72 \mathrm{~h}$ after exposure in both age groups and sexes. In 3-week-old animals, MN frequency was not significantly higher than in 12-week-old animals. In adult animals, $\mathrm{MN}$ frequency dropped back to baseline values $96 \mathrm{~h}$ after exposure. Three-week-old females returned to baseline values 2 weeks after exposure, while in males $\mathrm{MN}$ frequency remained increased.

At the dose of $5 \mu \mathrm{g} / \mathrm{kg}$, MN frequency increased in both age groups and sexes, peaking at $72 \mathrm{~h}$ in adults and at $48 \mathrm{~h}$ in 3-week-old animals (Figure 4). There was no significant difference in peak values between 3- and 12-week-old males. Three-week-old females had a significantly higher $\mathrm{MN}$ frequency than 12-week-old females.

Two weeks after exposure, MN frequency remained significantly increased only in 3-week-old males (Figure 4).

There was a significant difference $(P<0.001)$ in $M N$ elimination between age groups for all doses. Males had a significantly $(P<0.001)$ higher MN frequency than females (Table 1).

Some cells in the exposed animals, regardless of DES concentration, animal age, or sex, had several micronuclei in one reticulocyte.

\section{Discussion}

Estrogen is a hormone with genotoxic potential, which acts through its quinone metabolites. By inducing oxidants and aldehydes, they create mutagenic apurinic sites in DNA and cause lipid peroxidation (2). 


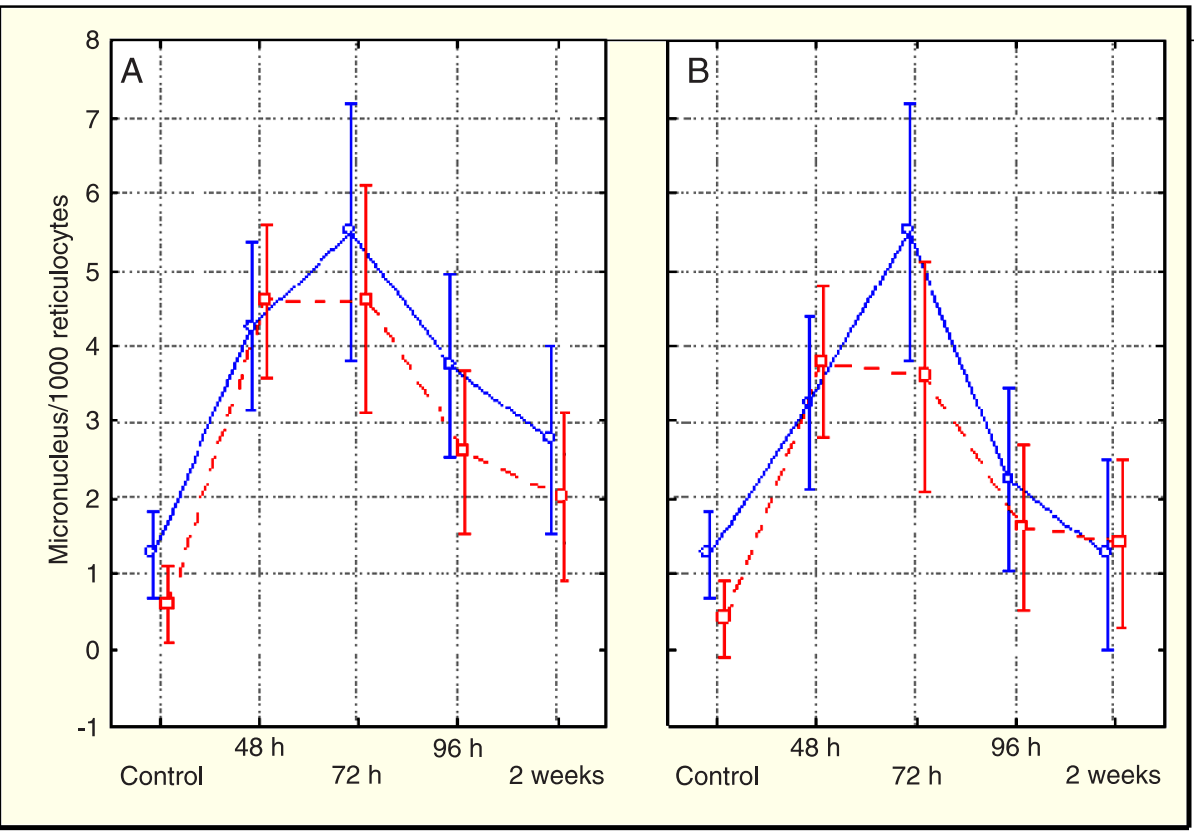

Figure 3. Micronucleus (MN) frequency in A, 3- and B, 12-week-old male (blue full line) and female (red dashed line) mice exposed to $0.5 \mu \mathrm{g} / \mathrm{kg}$ diethylstilbestrol. For each dose, age and sex, 5 animals were analyzed. Micronucleus frequency is presented per 1000 reticulocytes. Vertical bars indicate $95 \%$ confidence intervals. ANOVA for repeated measurements was used to compare responses at each sampling time.

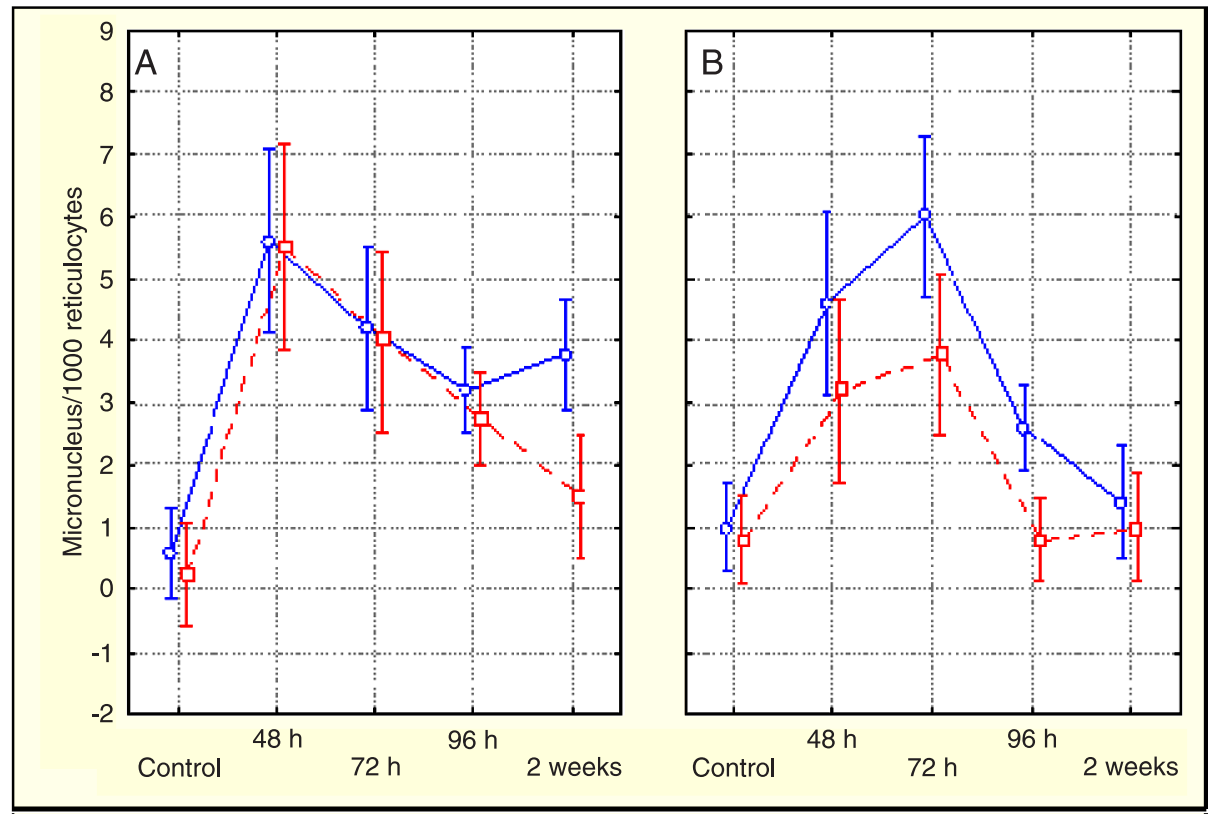

Figure 4. Micronucleus (MN) frequency in $A$, 3- and $B, 12$-week-old male (blue full line) and female (red dashed line) mice exposed to $5 \mu \mathrm{g} / \mathrm{kg}$ diethylstilbestrol. For each dose, age and sex, 5 animals were analyzed. Micronucleus frequency is presented per 1000 reticulocytes. Vertical bars indicate $95 \%$ confidence intervals. ANOVA for repeated measurements was used to compare responses at each sampling time. 
Table 1. Descriptive statistics regarding micronucleus frequency in 3- and 12-week-old mice exposed to $0.05,0.5$, and $5 \mu \mathrm{g} / \mathrm{kg}$ diethylstilbestrol 48,72 and $96 \mathrm{~h}$ and 2 weeks after exposure.

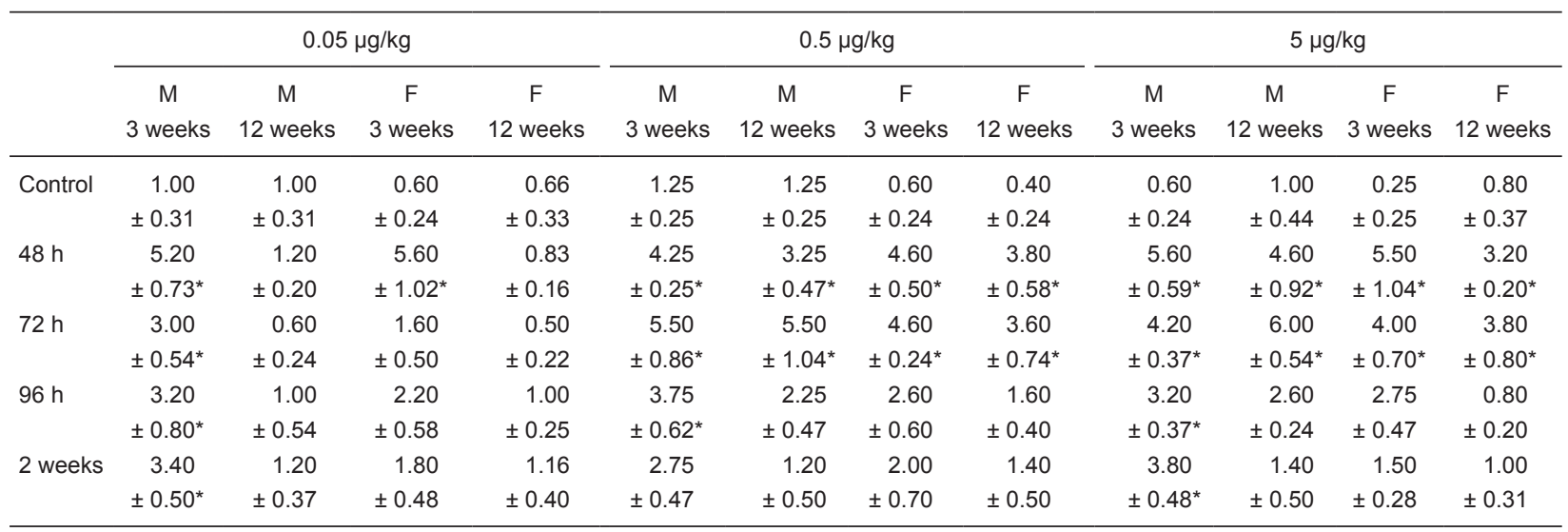

Data are reported as means $\pm S D$ per 1000 reticulocytes. Five animals were analyzed for each dose, sex, and age group. $M=$ male; $F$ $=$ female. ${ }^{*} \mathrm{P}<0.005$ for exposed animals compared to baseline frequencies (ANOVA for repeated measurements).

Estrogen-induced kidney tumors in animal models are characterized by highly aneuploid cells (92-94\%) as a consequence of centrosome amplification related to the overexpression of Aurora A and B proteins (19), which probably involves caspase $3(20)$. The ability of estrogen to interfere with tubulin polymerization is not related to its hormone activity (21).

DES is a well-known xenoestrogen that was used to prevent miscarriage between 1940 and 1971, when its application was banned because of the association established between in utero exposure and increased cancer incidence and non-neoplastic abnormalities of the reproductive system (22). Diethylstilbestrol seems to act through estrogen alpha receptor proteins (23). Like estrogens, this drug acts as a clastogen and aneugen through its quinone metabolites $(21,22,24)$.

In the present study, we used a starting dose of $5 \mu \mathrm{g} /$ $\mathrm{kg}$, reported to be genotoxic (25), and reduced it to 0.5 and $0.05 \mu \mathrm{g} / \mathrm{kg}$ to find the threshold of its genotoxic activity on animals of pre-pubertal and adult age.

For the first time, we have shown a clear difference between age and sex in the level of genotoxic damage caused by DES. At $0.05 \mu \mathrm{g} / \mathrm{kg}$, only pre-pubertal animals showed a significantly higher MN frequency, while this frequency did not differ from the negative control in adult animals. However, the higher dose of $0.5 \mu \mathrm{g} / \mathrm{kg}$ caused a significantly higher frequency of $\mathrm{MN}$ in both pre-pubertal and adult mice and could be suggested to be a threshold for adult animals. In adult animals, MN frequency reached control values $96 \mathrm{~h}$ after exposure, while in pre-pubertal animals it remained high for 2 weeks after exposure. Higher long-term genome damage detected in 3-week-old males may be the consequence of genome instability described after exposure to DES (26). One of the mechanisms responsible for this instability could be DNA hypomethylation (27). Estrogen-induced DNA methylation shows agerelated differences in animals (28). Hypomethylation can also be related to aneuploidy since it impairs the function of the DNA-binding proteins in the satellite region of the centromere (29). This suggests that aneuploidy associated with exposure to endocrine disruptors (19) could also have its origin in their demethylating potency. Methylation is also age-dependent. Neonatal exposure to DES causes permanent disturbances in the level of DNA methylation (30). However, this phenomenon has not been investigated in puberty, which is the final stage of maturation directed by hormones.

In the present study, the mitotic arrest detected in adult animals probably reached the peak in MN frequency at 72 $\mathrm{h}$ after exposure, while in young animals the highest $\mathrm{MN}$ frequency was detected $48 \mathrm{~h}$ after exposure to $5 \mu \mathrm{g} / \mathrm{kg}$ (at the dose of $0.5 \mu \mathrm{g} / \mathrm{kg}$ the difference in MN frequency between 48 and $72 \mathrm{~h}$ post-dose was not significant). In an in vitro model, DES was reported to cause mitotic arrest (31). The age difference in the level of mitotic arrest may be explained by the higher cell turnover in young animals.

Since the genotoxic activity of DES is similar to that of estrogen, our results show that pre-pubertal animals are more susceptible to genotoxic estrogen actions and that males are more susceptible than females.

The reason for this age- and sex-related difference needs to be elucidated. Pre-pubertal girls have eight times higher estrogen levels than boys of the same age (32). Additionally, sexual dimorphism in metabolism has been reported for a number of xenobiotics $(33,34)$. However, most studies still lack data about the age- and sex-specific 
metabolism of xenobiotics, and this leaves no other option to researchers but to use models or approximations based on measurements in adults $(34,35)$. Sex-specific DNA adduct production has been described in animal models. After exposure to estradiol, liver adduct formation was detected in male, but not in female, rats (36). Quinone reductase is known to reduce toxic quinones (26), which are the metabolites of estrogen and DES. The levels of this enzyme are age- and sex-specific, and as they are lower in males, this may contribute to a higher level of DES-induced free radicals in them than in females. In rats, higher levels of NADPH quinone reductase were detected in females than in males (37). This difference may be even more pronounced in the pre-pubertal period. A sex-specific impact on metabolism

\section{References}

1. Balthazart J, Ball GF. Is brain estradiol a hormone or a neurotransmitter? Trends Neurosci 2006; 29: 241-249.

2. Cavalieri E, Frenkel K, Liehr JG, Rogan E, Roy D. Estrogens as endogenous genotoxic agents - DNA adducts and mutations. J Natl Cancer Inst Monogr 2000; 75-93.

3. Watson WH, Yager JD. Arsenic: extension of its endocrine disruption potential to interference with estrogen receptormediated signaling. Toxicol Sci 2007; 98: 1-4.

4. Raymond-Whish S, Mayer LP, O'Neal T, Martinez A, Sellers MA, Christian PJ, et al. Drinking water with uranium below the U.S. EPA water standard causes estrogen receptor-dependent responses in female mice. Environ Health Perspect 2007; 115: 1711-1716.

5. Xie Y, Liu J, Benbrahim-Tallaa L, Ward JM, Logsdon D, Diwan BA, et al. Aberrant DNA methylation and gene expression in livers of newborn mice transplacentally exposed to a hepatocarcinogenic dose of inorganic arsenic. Toxicology 2007; 236: 7-15.

6. Roy D, Liehr JG. Estrogen, DNA damage and mutations. Mutat Res 1999; 424: 107-115.

7. Gonzalez M, Cabrera-Socorro A, Perez-Garcia CG, Fraser JD, Lopez FJ, Alonso R, et al. Distribution patterns of estrogen receptor alpha and beta in the human cortex and hippocampus during development and adulthood. J Comp Neurol 2007; 503: 790-802.

8. Quick EL, Parry EM, Parry JM. Do oestrogens induce chromosome specific aneuploidy in vitro, similar to the pattern of aneuploidy seen in breast cancer? Mutat Res 2008; 651: 46-55.

9. Inano $\mathrm{H}$, Yamanouchi $\mathrm{H}$, Suzuki K, Onoda M, Wakabayashi K. Estradiol-17 beta as an initiation modifier for radiationinduced mammary tumorigenesis of rats ovariectomized before puberty. Carcinogenesis 1995; 16: 1871-1877.

10. Tayama S, Nakagawa Y, Tayama K. Genotoxic effects of environmental estrogen-like compounds in $\mathrm{CHO}-\mathrm{K} 1$ cells. Mutat Res 2008; 649: 114-125.

11. Brody JG, Rudel RA, Michels KB, Moysich KB, Bernstein $\mathrm{L}$, Attfield KR, et al. Environmental pollutants, diet, physical activity, body size, and breast cancer: where do we stand in research to identify opportunities for prevention? Cancer 2007; 109: 2627-2634. has also been described for bisphenol $A$, an agent similar to DES (38).

The model proposed here may be incorporated into the Tier I test, the assay for pubertal female rodents designed to screen for xenoestrogen activity and recommended by the Endocrine Screening and Testing Advisory Committee $(39,40)$.

Like transplacental genotoxicology, pubertal genotoxicology is a complex issue. Both developmental periods require application of tools for biology systems, including pattern recognition techniques, cluster analysis, component and pathway analysis, and cognitive networks in order to obtain a reliable interpretation.

12. Newbold RR. Lessons learned from perinatal exposure to diethylstilbestrol. Toxicol Appl Pharmacol 2004; 199: 142150.

13. Gladek A, Liehr JG. Mechanism of genotoxicity of diethylstilbestrol in vivo. J Biol Chem 1989; 264: 16847-16852.

14. Thomas RD, Roy D. Base sequence-specific attack of stilbene estrogen metabolite(s) on the mitochondrial DNA: implications in the induction of instability in the mitochondrial genome in the kidney of Syrian hamsters. Int $\mathrm{J} \mathrm{Mol} \mathrm{Med}$ 2001; 7: 389-395.

15. Ozawa N, Oshimura M, McLachlan JA, Barrett JC. Nonrandom karyotypic changes in immortal and tumorigenic Syrian hamster cells induced by diethylstilbestrol. Cancer Genet Cytogenet 1989; 38: 271-282.

16. Prasad V, Garber SE, Luduena RF. Effect of diethylstilbestrol on the polymerization and alkylation of tubulin. Drug Dev Res 1999; 48: 104-112.

17. Roy D, Colerangle JB, Singh KP. Is exposure to environmental or industrial endocrine disrupting estrogen-like chemicals able to cause genomic instability? Front Biosci 1998; 3: d913-d921.

18. Hayashi M, Tice RR, MacGregor JT, Anderson D, Blakey DH, Kirsh-Volders $\mathrm{M}$, et al. In vivo rodent erythrocyte micronucleus assay. Mutat Res 1994; 312: 293-304.

19. Hontz AE, Li SA, Lingle WL, Negron V, Bruzek A, Salisbury $\mathrm{JL}$, et al. Aurora A and B overexpression and centrosome amplification in early estrogen-induced tumor foci in the Syrian hamster kidney: implications for chromosomal instability, aneuploidy, and neoplasia. Cancer Res 2007; 67: 2957-2963.

20. Decordier I, Cundari E, Kirsch-Volders M. Survival of aneuploid, micronucleated and/or polyploid cells: crosstalk between ploidy control and apoptosis. Mutat Res 2008; 651: 30-39.

21. Metzler M, Pfeiffer E. Effects of estrogens on microtubule polymerization in vitro: correlation with estrogenicity. Environ Health Perspect 1995; 103 (Suppl 7): 21-22.

22. Marselos M, Tomatis L. Diethylstilboestrol: I, pharmacology, toxicology and carcinogenicity in humans. Eur $\mathrm{J}$ Cancer 1992; 28A: 1182-1189.

23. Henley DV, Korach KS. Endocrine-disrupting chemicals use 
distinct mechanisms of action to modulate endocrine system function. Endocrinology 2006; 147: S25-S32.

24. Kayani MA, Parry JM. The detection and assessment of the aneugenic potential of selected oestrogens, progestins and androgens using the in vitro cytokinesis blocked micronucleus assay. Mutat Res 2008; 651: 40-45.

25. Halling A, Forsberg JG. Ovarian reproductive function after exposure to diethylstilbestrol in neonatal life. Biol Reprod 1990; 43: 472-477.

26. Roy D, Liehr JG. Temporal decrease in renal quinine reductase activity induced by chronic administration of estradiol to male Syrian hamsters. Increased superoxide formation by redox cycling of estrogen. J Biol Chem 1998; 263: 3646-3651.

27. Jones PA. DNA methylation and cancer. Oncogene 2002; 21: $5358-5360$.

28. Thakur MK, Kaur J. Methylation of DNA and its modulation by estrogen in the uterus of aging rats. Cell Mol Biol 1992; 38: $525-532$.

29. Stopper H, Eckert I, Wagener IP, Schultz WA. Formation of micronuclei and inhibition of topoisomerase II in the comet assay in mammalian cells with altered DNA methylation. Recent Results Cancer Res 1997; 143: 184-192.

30. Bombail V, Moggs JG, Orphanides G. Perturbation of epigenetic status by toxicants. Toxicol Lett 2004; 149: 51-58.

31. Lehmann L, Metzler M. Bisphenol A and its methylated congeners inhibit growth and interfere with microtubules in human fibroblasts in vitro. Chem Biol Interact 2004; 147: 273-285.

32. Klein KO, Baron J, Colli MJ, McDonnell DP, Cutler GB Jr.
Estrogen levels in childhood determined by an ultrasensitive recombinant cell bioassay. J Clin Invest 1994; 94: 24752480.

33. Gustafsson JA, Mode A, Norstedt G, Skett P. Sex steroid induced changes in hepatic enzymes. Annu Rev Physiol 1983; 45: 51-60.

34. Wauthier V, Waxman DJ. Sex-specific early growth hormone response genes in rat liver. Mol Endocrinol 2008; 22: 19621974.

35. Yager JD. Endogenous estrogens as carcinogens through metabolic activation. J Natl Cancer Inst Monogr 2000; 6773.

36. Feser W, Kerdar RS, Blode H, Reimann R. Formation of DNA-adducts by selected sex steroids in rat liver. Hum Exp Toxicol 1996; 15: 556-562.

37. Augustine LM, Fisher CD, Lickteig AJ, Aleksunes LM, Slitt $\mathrm{AL}$, Cherrington NJ. Gender divergent expression of Nqo1 in Sprague Dawley and August Copenhagen x Irish rats. $J$ Biochem Mol Toxicol 2008; 22: 93-100.

38. Hanioka N, Jinno H, Nishimura T, Ando M. Suppression of male-specific cytochrome P450 isoforms by bisphenol $\mathrm{A}$ in rat liver. Arch Toxicol 1998; 72: 387-394.

39. Kim HS, Shin JH, Moon HJ, Kim TS, Kang IH, Seok JH, et al. Evaluation of the 20-day pubertal female assay in SpragueDawley rats treated with DES, tamoxifen, testosterone, and flutamide. Toxicol Sci 2002; 67: 52-62.

40. Laws SC, Stoker TE, Ferrell JM, Hotchkiss MG, Cooper RL. Effects of altered food intake during pubertal development in male and female Wistar rats. Toxicol Sci 2007; 100: 194202. 